07ICES-122

\title{
Testing of the Multi-Fluid Evaporator Engineering Development Unit
}

\author{
Gregory Quinn, Ed O’Connor, Ken Riga \\ Hamilton Sundstrand \\ Molly Anderson, David Westheimer \\ NASA Johnson Space Center
}

\begin{abstract}
Hamilton Sundstrand is under contract with the NASA Johnson Space Center to develop a scalable, evaporative heat rejection system called the Multi-Fluid Evaporator (MFE). It is being designed to support the Orion Crew Module and to support future Constellation missions. The MFE would be used from Earth sea level conditions to the vacuum of space. The current Shuttle configuration utilizes an ammonia boiler and flash evaporator system to achieve cooling at all altitudes. The MFE system combines both functions into a single compact package with significant weight reduction and improved freeze-up protection. The heat exchanger core is designed so that radial flow of the evaporant provides increasing surface area to keep the back pressure low. The multiple layer construction of the core allows for efficient scale up to the desired heat rejection rate. The full scale MFE prototype will be constructed with four core sections that, combined with a novel control scheme, manage the risk of freezing the heat exchanger cores.

A sub-scale MFE engineering development unit (EDU) has been built, and is identical to one of the four sections of a full scale prototype. The EDU has completed testing at Hamilton Sundstrand. The overall test objective was to determine the thermal performance of the EDU. The first set of tests simulated how each of the four sections of the prototype would perform by varying the chamber pressure, evaporant flow rate, coolant flow rate and coolant temperature. A second set of tests was conducted with an outlet steam header in place to verify that the outlet steam orifices prevent freeze-up in the core while also allowing the desired thermal turn-down ratio. This paper discusses the EDU tests and results.
\end{abstract}

\section{INTRODUCTION}

All launch and re-entry manned space capsules to date have required evaporative heat sinks to provide cooling prior to radiator deployment and during periods of high heat load or under adverse thermal radiation environments. Typically, the heat transport fluid must be cooled to $3.3^{\circ} \mathrm{C}-7.2^{\circ} \mathrm{C}\left(38-45^{\circ} \mathrm{F}\right)$ to satisfy humidity control needs within the manned spacecraft. Water is the most weight-efficient evaporant with a latent heat of $2326 \mathrm{~kJ} / \mathrm{kg}$ (1000 BTU/lb). In a weight-limited spacecraft, water must be utilized whenever possible. For evaporation to occur, the evaporator exhaust pressure must be much less than the fluid saturation pressure corresponding to the required heat sink temperature. To meet the environmental control and life support system (ECLSS) needs, this is typically a temperature of $2.2^{\circ} \mathrm{C}\left(36^{\circ} \mathrm{F}\right)$ with a corresponding saturation pressure of 5.2 Torr $(0.10$ psia). Thus, use of water as an evaporant is limited to altitudes above 33500 meters $(110,000 \mathrm{ft})$ where the ambient pressure is low enough to allow evaporation at the low 
temperatures required. At lower altitudes, less weight-efficient fluids with higher saturation pressures must be utilized. Ammonia, with a latent heat of $1230 \mathrm{~kJ} / \mathrm{kg}$ (530 $\mathrm{BTU} / \mathrm{lb})$ and a saturation pressure of 3775 Torr $(73 \mathrm{psia})$ at $4.4^{\circ} \mathrm{C}\left(40^{\circ} \mathrm{F}\right)$ is the next most weight-efficient evaporant. However, materials compatibility, environmental and safety considerations are concerns associated with ammonia. There are fewer concerns associated with the next weight-efficient level of evaporants, which focuses on Freons or Freon alternatives with latent heats in the range of 162-232 kJ/kg (70-100 BTU/lb). These constraints drove the MFE development program to select R134a for a secondary coolant. The concept of operations requires drying of the evaporant passage of one evaporant prior to introducing the other in order to avoid any possibility of creating corrosive mixtures of water and R134a.

The most significant technical challenge associated with evaporating water in space is preventing icing. Weight savings associated with water's latent heat more than compensate for the struggle involved in overcoming this extremely difficult technical challenge. Water's triple point pressure is 4.6 Torr (0.089 psia) with a triple point temperature of $0^{\circ} \mathrm{C}\left(32^{\circ} \mathrm{F}\right)$, and freezes when exposed to pressures below this level. Since the evaporator exhaust pressure is approximately 5.2 Torr ( 0.10 psia), the working pressure differential above freezing is only 0.6 Torr (0.011psid); compared to a 1140 Torr (21 psid) differential associated with R134a.

Apollo faced the issue by incorporating an active back-pressure control; however, this design was prone to dryout and erratic control. For heat rejection under vacuum conditions, Hamilton Sundstrand's invention of the sublimator provided evaporant cooling for the Lunar Module and all space suit cooling systems to date. In it, evaporant water freezes in a porous plate where the freezing/sublimation progression through the plate is a self-regulating evaporant flow control at a constant sink temperature of $0^{\circ} \mathrm{C}$ $\left(32^{\circ} \mathrm{F}\right)$. It is a simple, compact approach that works quite effectively. However, the contaminants present in spacecraft plumbing plug the porous plate and limit its life between maintenance operations to several hundred hours. Hamilton Sundstrand also developed the Flash Evaporator for the Shuttle program. The Flash Evaporator is a large cylinder (11 inch diameter) with the heat transport fluid flowing longitudinally through the cylinder's wall. Its interior is a vacuum chamber operating below the triple point in which water is sprayed at $15 \mathrm{~m} / \mathrm{sec}(50 \mathrm{ft} / \mathrm{sec})$ onto the cylinder's interior walls. The short exposure time to vacuum (20 milliseconds) and the high energy flux at the wall allows water to evaporate before it freezes. The high heat flux requirement drives the use of aluminum heat transfer surfaces in spite of their susceptibility to corrosion during long-term usage.

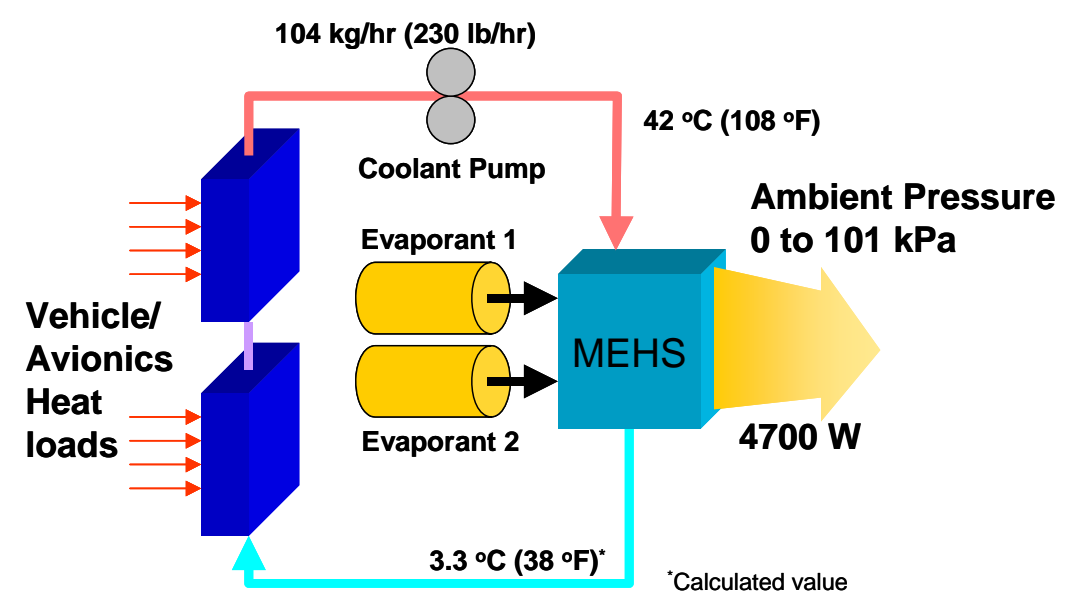

Figure 1: Simplified CEV Cooling Loop 
Hamilton Sundstrand has been developing the radial flow, multi-fluid evaporator to address the drawbacks associated with past solutions to spacecraft heat rejection. A MFE proof of concept was constructed at Hamilton Sundstrand in 2004 and tested in 2005. Further development of the technology is continuing via the Delivery Order 3 (DO3) of the Crew Robotics and Vehicle Equipment (CRAVE) contract with NASA Johnson Space Center. The contract calls for the construction and testing of an engineering development unit (EDU), followed by the construction of a full scale prototype for testing at Johnson Space Center (1). The EDU was built in October 2006 and completed testing at Hamilton Sundstrand in February 2007.

The delivery order called for an evaporator that is capable of providing $4700 \mathrm{~W}$ of heat rejection in a design capable of operation from Earth to orbit and on the moon. A simplified schematic of the concept is presented in Figure 1 with the design criteria summarized in Table 1. The conceptual design of the EDU was completed in November of 2005. The EDU was sized for the contract value of $4.7 \mathrm{~kW}$ of heat rejection. At that time, the Crew Exploration Vehicle thermal rejection estimate was increased to $6.0 \mathrm{~kW}$. There seemed to be margin in the design of the EDU, so the team decided to test the unit at $6.0 \mathrm{~kW}$. The test plan for the EDU was updated to focus on conditions that represented a full scale power of $6.0 \mathrm{~kW}$.

Table 1: MEHS Design Criteria

\begin{tabular}{|l|c|c|}
\hline Parameter & $\begin{array}{c}\text { Requirement } \\
\text { (SI) }\end{array}$ & $\begin{array}{c}\text { Requirement } \\
\text { (English) }\end{array}$ \\
\hline Coolant Fluid & Water & Water \\
\hline Fluid (typical) & $104 \mathrm{~kg} / \mathrm{hr}$ & $230 \mathrm{lb} / \mathrm{hr}$ \\
\hline Fluid Flow Rate & $4700 \mathrm{watts}$ & $16,000 \mathrm{BTU} / \mathrm{hr}$ \\
\hline Heat Rejection (Design Point) & $3: 1$ & $3: 1$ \\
\hline Minimum Heat Rejection Turndown Ratio & $43^{\circ} \mathrm{C}$ & $109^{\circ} \mathrm{F}$ \\
\hline Maximum Coolant Inlet Temperature & $4.4^{\circ} \mathrm{C}$ & $40^{\circ} \mathrm{F}$ \\
\hline Maximum Coolant Outlet Temperature & $44 \mathrm{kPa}$ & $6.5 \mathrm{psid}$ \\
\hline Maximum Coolant Pressure Drop & $689 \mathrm{kPa}$ & $100 \mathrm{psia}$ \\
\hline Coolant Pressure (typical) & \multicolumn{2}{|c|}{14.7 psia } \\
\hline Evaporant & At Altitude - Water \\
\hline Fluid & Launch \& Landing - R134a \\
\hline Exhaust Pressure & 0 to $101 \mathrm{kPa}$ & 0 to 14.7 psia \\
\hline Feed Pressure & \multicolumn{2}{|c|}{ storage location. } \\
\hline Feed Temperature & Compatible with vehicle evant \\
\multicolumn{2}{|c|}{1 g in one axis } \\
\hline Acceleration Environment & \multicolumn{2}{|c|}{ Operable in zero to one gravity } \\
\hline Gravity Sensitivity & \multicolumn{2}{|c|}{} \\
\hline
\end{tabular}

The full scale prototype was sectioned into four modules. The closed loop coolant flows through the modules in series, getting progressively colder until it leaves the last module at $4.4^{\circ} \mathrm{C}\left(40^{\circ} \mathrm{F}\right)$. Evaporant feed is plumbed to the modules in parallel. Figure 2 shows a simplified schematic of the module's arrangement. 


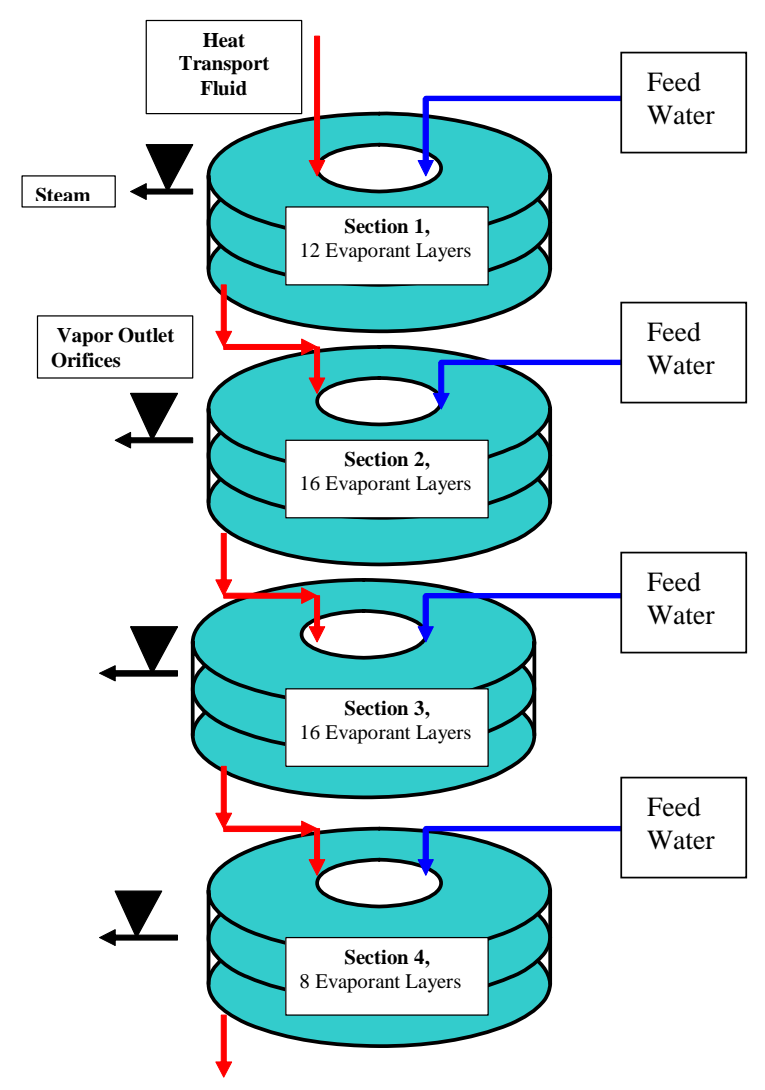

Figure 2: Multi-Fluid Evaporator Prototype Schematic

\section{EXPERIMENTAL SETUP}

Testing was conducted at Hamilton Sundstrand in the rig 8 vacuum chamber. This is the EMU sublimator rig and is capable of pumping out the water vapor while maintaining a chamber pressure as low as 0.08 Torr. It has an inside diameter of 23 inches and a depth of 28 inches. It can deliver conditioned feed water and coolant water to the test article. Feed water was delivered to the EDU via a needle valve.

The MFE EDU is made of twenty five heat exchanger layers. There are twelve evaporant layers interspersed between thirteen coolant layers. The footprint is a quarter circle with three integral fluid headers; coolant inlet, coolant outlet and evaporant. The active portion of the heat exchanger has an inside radius of two inches

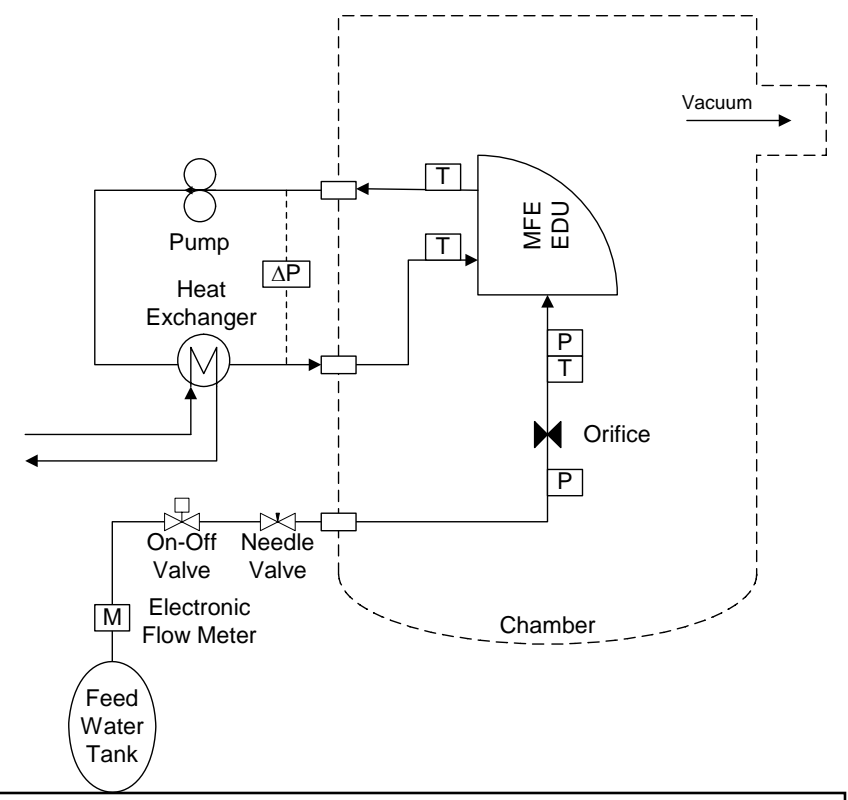

Figure 3: EDU Test Schematic and an outside radius of five inches. The EDU was tested in two configurations. The 
first configuration did not have the outlet vapor header attached to it (Figure 4). The second configuration had the outlet vapor header welded onto it. The header had a removable orifice plate in it (Figure 5).

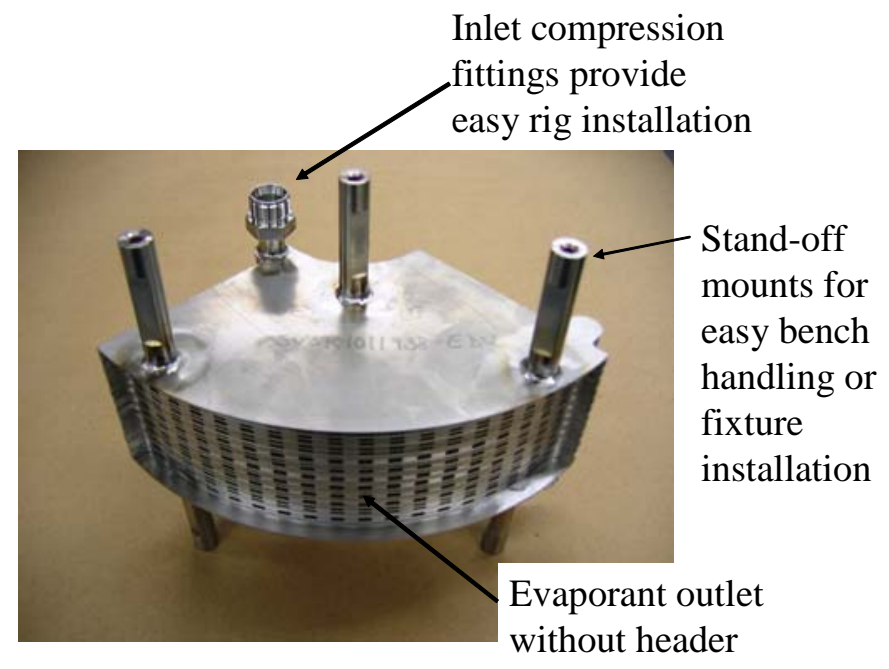

Figure 4: Engineering Development Unit without vapor outlet header

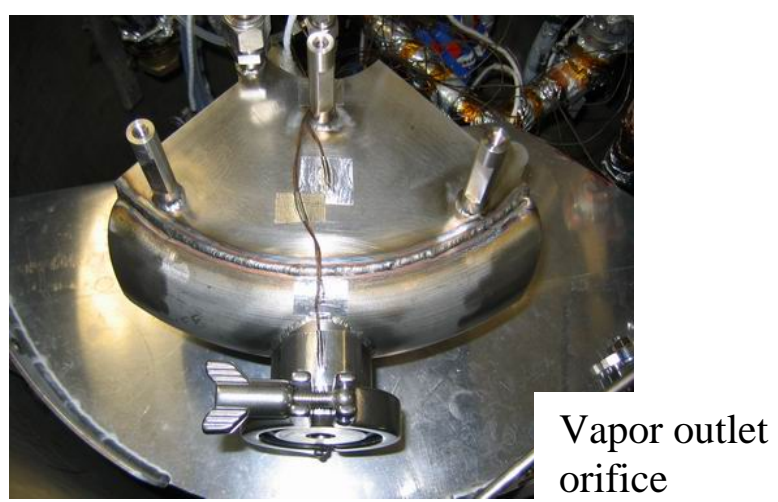

Figure5: Engineering Development Unit with vapor outlet header and orifice

\section{PROCEDURES}

The overall test objective was to determine the thermal performance of the Multi-Fluid Evaporator EDU. The first tests were conducted to simulate how each section of the prototype would perform by varying the pressure that the evaporant discharges to and the coolant's flow rate and temperature. The feed flow rate was increased to the point of significant liquid water carry-over for each test condition. The adequacy of the feed water inlet orifices were also determined. The inlet orifices had to be small enough to give the feed water metering valve control over the flow without being so small that it choked the flow.

The first set of tests were run according to the steps below, without the vapor header.

1. Degas the feed water to $2-3$ psia

2. Chill the feed water to $40^{\circ} \mathrm{F}$

3. Condition the vacuum chamber by evacuating it to 0.1 psia

4. Turn the coolant flow on and set it to $293 \mathrm{lb} / \mathrm{hr}$ and $110^{\circ} \mathrm{F}$

5. Allow the EDU temperature to stabilize

6. Turn on the feed water at $0.5 \mathrm{lb} / \mathrm{hr}$ and allow the unit reaches steady state conditions

7. Increase the feed water flow rate in steps, recording the results at each step

8. Observe and note any feed water carry over

A second round of tests were conducted to verify that the sections would perform properly with the vapor header and outlet vapor orifices in place. These tests were conducted by setting the vacuum chamber below 0.04 psia, the coolant to the desired flow rate and temperature, and the feed water to the target flow rate. All thermal, 
pressure and flow data were recorded and observations were made of the feed water carry over.

Table 2: EDU Test Matrix

\begin{tabular}{|c|c|c|c|c|c|}
\hline $\begin{array}{c}\text { Test } \\
\text { Number }\end{array}$ & $\begin{array}{c}\text { Coolant Flow } \\
\text { Rate } \\
\mathrm{lb} / \mathrm{hr}\end{array}$ & $\begin{array}{c}\text { Coolant } \\
\text { Inlet Temp } \\
\text { Deg F }\end{array}$ & \begin{tabular}{|r}
$\begin{array}{l}\text { Chamber } \\
\text { Pressure }\end{array}$ \\
psia \\
\end{tabular} & $\begin{array}{c}\text { Feed Flow } \\
\text { rate(s) } \\
\mathrm{lb} / \mathrm{hr}\end{array}$ & Notes \\
\hline \multicolumn{3}{|c|}{ Testing without outlet header } & & & \\
\hline $1 a-c$ & 293 & 110 & 0.100 & 0.5 to $\max$ & Check-out Tests \\
\hline 2 & \multirow{4}{*}{293} & 109.8 & 0.143 & \multirow{3}{*}{0.5 to $\max$} & Section 1 Test \\
\hline 3 & & 87.0 & 0.143 & & Section 1 uses $9.8 \mathrm{lb} / \mathrm{hr}$ when the \\
\hline 4 & & 71.3 & 0.089 & & prototype rejects $6 \mathrm{~kW}$ \\
\hline 5 & & 109.8 & 0.143 to 0.002 & $\max ^{*}$ & \\
\hline 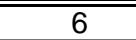 & \multirow{4}{*}{224} & 75.1 & 0.144 & \multirow{3}{*}{0.5 to $\max$} & Section 2 Test \\
\hline 7 & & 67.8 & 0.145 & & Section 2 uses $6.44 \mathrm{lb} / \mathrm{hr}$ when the \\
\hline 8 & & 59.3 & 0.091 & & prototype rejects $6 \mathrm{~kW}$ \\
\hline 9 & & 75.1 & 0.143 to 0.002 & $\max ^{*}$ & \\
\hline 10 & \multirow{4}{*}{224} & 52.3 & 0.141 & \multirow{3}{*}{0.5 to $\max$} & Section 3 Test \\
\hline 11 & & 50.6 & 0.107 & & Section 3 uses $2.06 \mathrm{lb} / \mathrm{hr}$ when the \\
\hline 12 & & 49.6 & 0.089 & & prototype rejects $6 \mathrm{~kW}$ \\
\hline 13 & & 52.3 & 0.141 to 0.002 & $\max ^{*}$ & \\
\hline$\overline{14}$ & \multirow{2}{*}{423} & 45.0 & 0.097 & 0.5 to $\max$ & Section 4 Test \\
\hline 15 & & 45.0 & 0.097 to 0.002 & $\max ^{*}$ & Section 4 uses $1.41 \mathrm{lb} / \mathrm{hr}$ \\
\hline$\overline{16}$ & \multirow{2}{*}{$150-450$} & 109.8 & 0.143 & \multirow{2}{*}{$\max ^{*}$} & \\
\hline 17 & & 52.3 & 0.141 & & \\
\hline \multicolumn{6}{|c|}{ Testing with outlet header } \\
\hline$\frac{18}{19}$ & 293 & \begin{tabular}{r|}
109.8 \\
71.3
\end{tabular} & & \multirow{6}{*}{0.5 to $\max$} & Section 1 Test \\
\hline 20 & \multirow{2}{*}{224} & 75.1 & & & \multirow{2}{*}{ Section 2 Test } \\
\hline 21 & & 59.3 & & & \\
\hline 22 & \multirow{2}{*}{224} & 52.3 & & & \multirow{2}{*}{ Section 3 Test } \\
\hline 23 & & 49.6 & & & \\
\hline 24 & 423 & 45.0 & & & Section 4 Test \\
\hline * & \multicolumn{5}{|c|}{$\begin{array}{l}\text { maximum feed flow rate without carry-over fol } \\
\text { Increase Feed water in } 0.5 \mathrm{lb} / \mathrm{hr} \text { increments } \\
\text { Decrease Chamber pressure in } 0.01 \text { psia incre } \\
\text { Chill feed water to } 40 \mathrm{~F} \\
\text { Deqass Feed water to } 2 \text { psia }\end{array}$} \\
\hline
\end{tabular}

\section{RESULTS}

The thermal performance tests, conducted without the vapor outlet orifice, resulted in several findings. The first finding was that the evaporant core met the $4.7 \mathrm{~kW}$ performance mark with minimal liquid water carry over. When the core was fed excess water it would also meet the $6.0 \mathrm{~kW}$ mark. However, liquid evaporant carry over should be minimized or eliminated in order to use the minimum amount of evaporant possible for a given heat load and to prevent complications that carry over can cause downstream of the evaporator. The second major finding was that there is coolant maldistribution in the radial flow coolant layers. Coolant maldistribution caused cold spots that reduced the efficiency of the heat exchanger, which led to the water carry over at the edges and biased all of the thermal performance and thermal verification results. The orientation of the heat exchanger was found to affect performance, as did the temperature of the feed water. These major findings are summarized in Table 3. The table shows the coolant outlet temperature that was achieved when there was water carry over at the edges (Edge) 
and water carry over in most of the evaporant core (Core). The percentages are the percent of heat load achieved. Green boxes represent conditions that exceeded the target cooling, yellow ones met cooling and red ones fell short of the target cooling rate. Minor findings included data on hysteresis, degassing the feed water, and the feed water needle valve and orifices.

The thermal verification tests identified issues with the header and how the small amount of liquid water carry-over affected the performance with them in place. The header collected the water until it reached the level of the outlet orifice. The excess water spit out of the vapor orifice, with the potential to freeze and block the passage. Development and further testing of the orifice mitigated this issue. However, the liquid water pooled in the header still forced the EDU to be run with a reduced thermal load.

Table 3: Thermal Performance Test Results.

\begin{tabular}{|c|c|c|c|c|c|c|}
\hline Orientation & $\begin{array}{c}\text { Feed Water } \\
\text { Inlet } \\
\text { Temperature }\end{array}$ & $\begin{array}{c}\text { Required Coolant } \\
\text { Outlet Temp at } \\
109 \text { inlet }\end{array}$ & \multicolumn{2}{|c|}{$4.7 \mathrm{~kW}$} & \multicolumn{2}{|c|}{$6.0 \mathrm{~kW}$} \\
\hline & $\operatorname{deg} F$ & $\operatorname{deg} F$ & Edge & Core & Edge & Core \\
\hline horizontal & 41 & 75.1 & $\begin{array}{c}75.8 \\
(97 \%)\end{array}$ & $\begin{array}{c}68.3 \\
(117 \%)\end{array}$ & $\begin{array}{c}78.8 \\
(85 \%)\end{array}$ & $\begin{array}{c}71.1 \\
(105 \%)\end{array}$ \\
\hline horizontal & 72 & 75.1 & $\begin{array}{c}79.1 \\
(86 \%)\end{array}$ & $\begin{array}{c}75.8 \\
(97 \%)\end{array}$ & $\begin{array}{c}84.5 \\
(73 \%)\end{array}$ & \\
\hline upwards & 72 & 75.1 & & & $\begin{array}{c}67.2 \\
(120 \%)\end{array}$ & \\
\hline
\end{tabular}

\section{Thermal Performance Tests}

The first set of thermal performance tests were conducted as check-out tests and resulted in several minor findings. First, the original needle valve that controlled the feed water flow rate was too large. It was replaced with a micrometer needle valve which performed well for the rest of the tests. Feed water inlet orifices of sizes ranging from 0.007 inch diameter to 0.019 inch diameter were tested in the rig. Each orifice was found to flow the desired rate of water and provide good flow rate control with the micrometer needle valve. Another minor finding was that the unit did not exhibit hysteresis. A set of conditions could be repeated at steady state no matter what it had previously been set to. The system would reach steady state in five to ten minutes after changing the feed flow or coolant flow. Finally, the tests verified that the feed water should be degassed prior to running the tests. Degassing the feed water from 14.7 psia to 5.0 psia resulted in a $17 \%$ increase in performance.

The first major finding was that the evaporant core performed well. The evaporant fins adequately distributed the feed water and prevented liquid water from channeling where the fin sheets met the closure bars and other fin sheets. The low pressure drop in the evaporant layers met the performance predictions and contributed to the core's overall heat rejection capacity. The core also performed well with

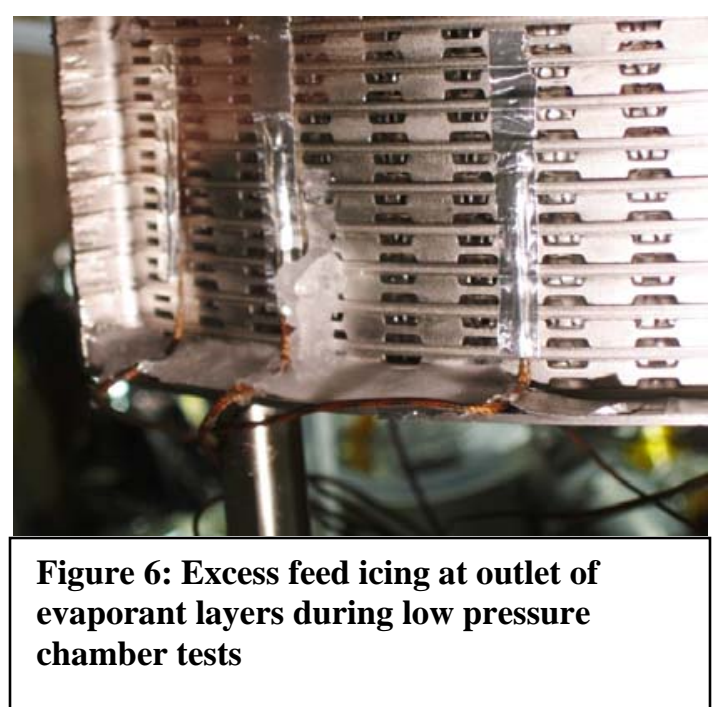


regard to icing. Although the vapor outlet orifices are designed to keep the core above the triple point of water, some of the thermal performance tests were conducted with chamber pressures below the triple point, so that the EDU's icing tolerance could be evaluated. At high coolant temperatures the only ice to form was from the water carryover. The feed water inside of the core remained liquid (Figure 6). At low coolant temperatures (below $50^{\circ} \mathrm{F}$ ) ice did form inside the evaporant layers, which resulted in an increased back-pressure. If the unit was run this way indefinitely, it would have begun to look like a sublimator. Fortunately, the EDU was strong enough to accommodate the ice.

The second major finding was that the coolant distribution within the layers created local areas of feed water carry-over. During most tests, the feed water flow rate was increased until carry-over was detected. The carry-over first appeared on the right and left sides of the EDU. As the flow rate increased further, the liquid carry-over spread inwards toward the center of the EDU. These observations strongly indicated that the coolant flow distribution was causing colder regions near the left and right edges that would not support as much evaporation as the warmer center. Figure 7 shows the intended coolant flow distribution, and Figure 8 shows a notional sketch of what the coolant may be doing. Table 3 shows that the coolant outlet temperature achieved with feed water breakthrough at the edge was significantly higher than the coolant outlet temperature achieved with feed water breakthrough in most of the core. Fortunately, evaluating and correcting the coolant flow distribution is an engineering task that can readily be accomplished for a

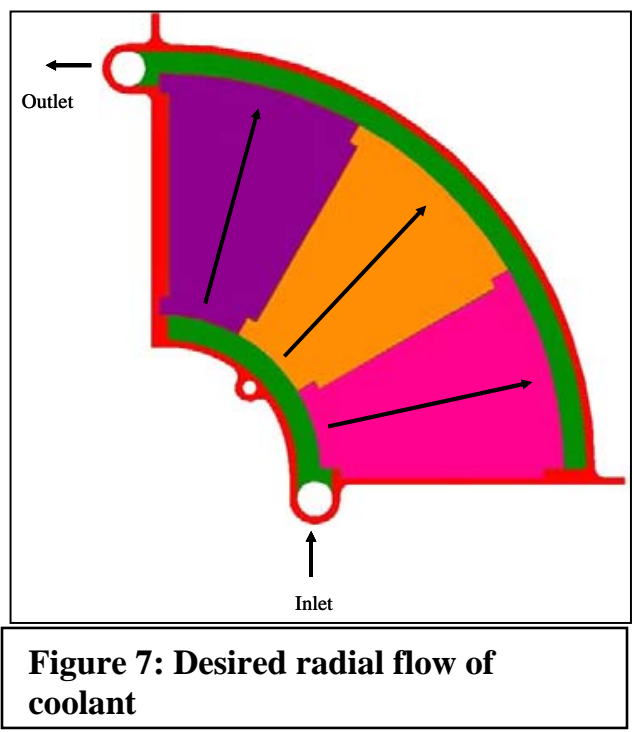

more flight-like MFE design.

The last major finding from the thermal performance tests was that two-phase flow in the headers of the unit affected its performance. The EDU was not meeting performace during the check-out tests, which were run with a $70^{\circ} \mathrm{F}$ feed water temperature. The check-out tests showed that the pressure inside the feed water
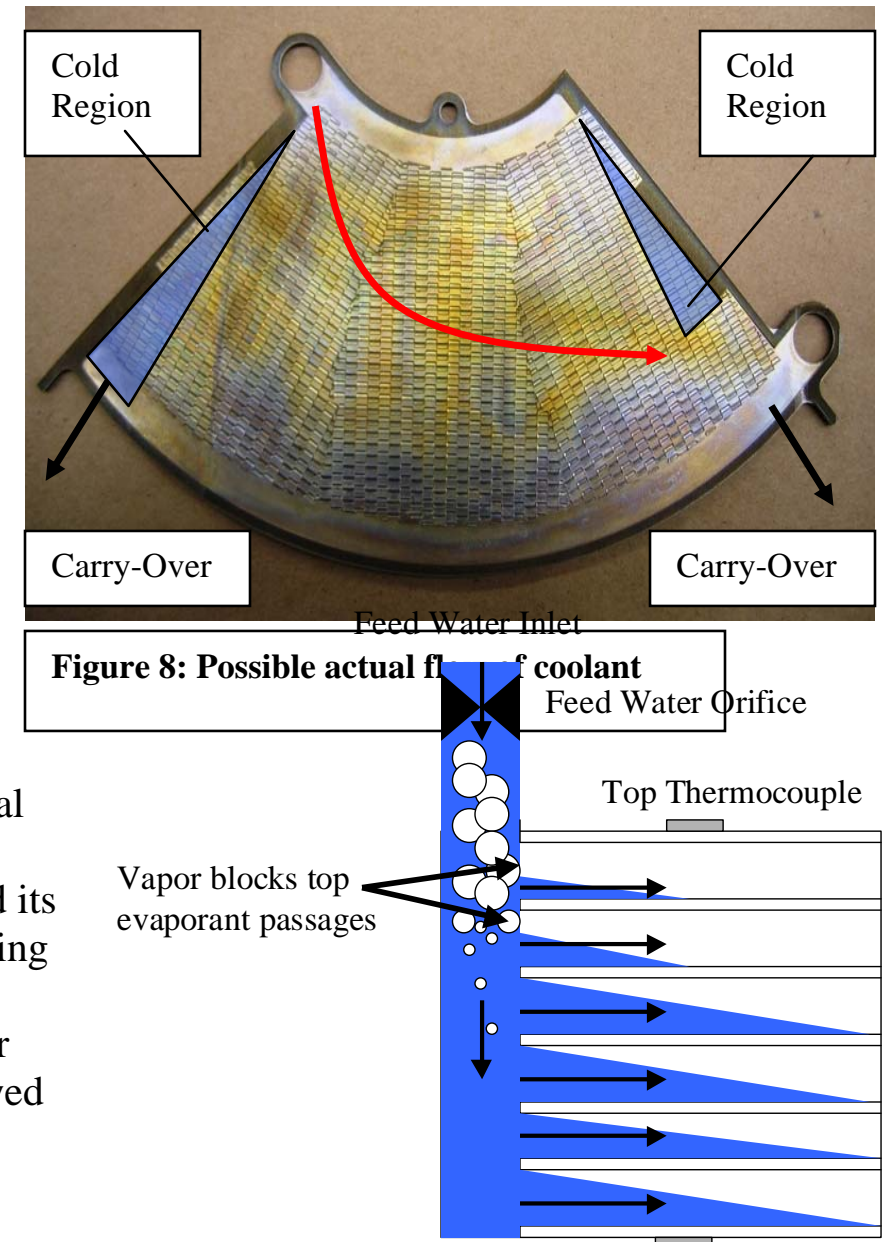

Bottom Thermocouple

Figure 9: Flashing in header blocks top evaporant layers 
header was below the vapor pressure of the water, so flashing was occuring inside the header. The feed water would evaporate until it reached the saturation temperature of about $40^{\circ} \mathrm{F}$. This amount of evaporation creates a 4000:1 volumetric expansion of water in the orifice. This is much greater than the volumetric expansion caused by disolved gases, which at 14.7 psia is 2.3:1 and at 2 psia is only 0.3:1. Also, the temperature of the top layer of coolant was significantly higher than the temperature of the bottom coolant layer. This indicated that the water vapor created in the header was blanketing the top layers of the EDU while the remaining liquid dropped to the bottom of the headers (Figure 9). So additional tests were conducted to evaluate the effect of gravity on the EDU performance and the effect of feed water temperature on the EDU. The effect of gravity was tested by running the EDU pointing upwards and pointing downwards (Figure 10). When the EDU was pointed upwards it acted like a pool boiler, creating a significant boost in performance. When the unit was pointed downward, the feed water simply dropped out of the unit, resulting in exceedingly poor performance. All subsequent tests were conducted with the EDU in a horizontal position. Despite the loss in performance caused by two phase flow in the header, this position most closely represented performance in microgravity. Feed water temperature tests showed that two phase flow in the headers was adequately managed by chilling the feed water to $40^{\circ} \mathrm{F}$. This eliminated the flashing in the header, which increased the EDU's performance by 23.\%.

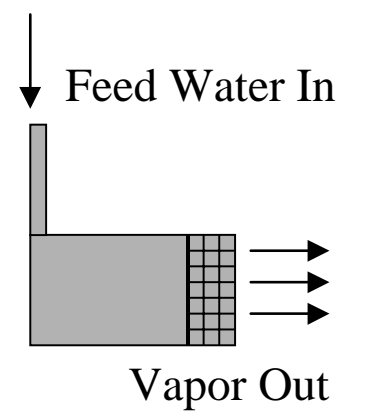

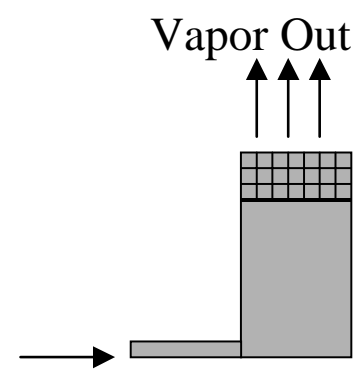

Feed Water In

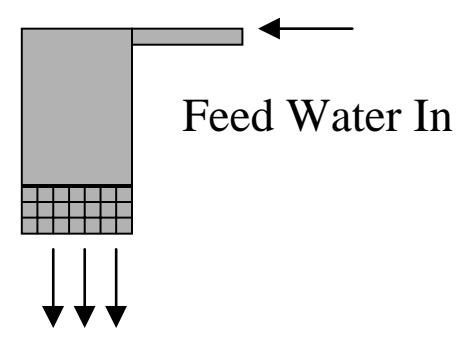

Vapor Out

\section{Horizontal Upwards Downwards}

Figure 10: EDU Testing Orientations

\section{Thermal Verification Tests}

Testing with the EDU header and vapor orifice in place showed that the small amount of liquid carry-over at the edges altered the performance when compared with the testing without the header, and needed to be managed with changes to the orifice design. Thermal performance testing showed that small amounts ( $5 \%)$ of liquid water carryover was present at the edges of the EDU at feed flow rates below those that would utilize the entire core. So, the thermal verification tests were conducted at conditions that would result in small amounts of carry-over at the edges. Observations during these tests revealed that, over the course of about fourty-five minutes, the bottom of the vapor header would fill up with water. This caused the EDU performance to drop off in two ways. First, the excess water in the core back-pressured the lower evaporant layers 
causing the saturation temperature and hence the sink temperature to rise. This decreased the amount of water the unit could evaporate and increased the amount of liquid carryover. The result was that the EDU with the header could only provide an equivalent heat rejection rate of $3.0 \mathrm{~kW}$ (scaled for the prototype).

The first set of vapor outlet orifices that were tested proved incompatible with liquid water carry-over. The original orifices were straight holes drilled in a $1 / 4$ inch plate. The sharp edge on the inside face of the orifice caused eddy currents within the header. These low pressure vortices were below the triple point of water, and drops of liquid would freeze in them. Over time, small sheets of ice built up in the eddys and slid into the orifice. The ice increased the pressure in the header, then broke off the orifice before growing again. Increases in the header pressure cut back on the performance, causing a periodic swing in the EDU's cooling capacity. The problem of eddy currents was eliminated by adding a $1 / 4$ inch round to the inside of the orifice plate.

Ice necked down the orifice in a second way when it stuck to the stainless steel plate. Water would enter the orifice, then freeze and stick at the outlet. This issue was addressed by adding a very thin layer of Brakote o-ring lubricant to the metal orifice. Braykote made the orifice ice-phobic for close to an hour until it began to wear off. Studies have demonstrated that Teflon is very good at shedding ice (2), so the prototype will be made with Teflon orifices to eliminate the need to periodically re-apply Braykote.

\section{DISCUSSION}

The fundamental technology of the Multi-Fluid Evaporator is contained in its ability to effectively evaporate water through a passive back pressure orifice out to hard vacuum. The engineering development unit has proven out this technology. The core of the heat exchanger was shown to be capable of rejecting the $4.7 \mathrm{~kW}$ it was designed for with minimal carry-over. The vapor outlet orifice was proven to keep the heat exchanger above the triple point of water to prevent freezing of the core. With these challenges met, the issues identified during the EDU testing can be addressed to increase the performance of the technology.

The coolant flow distribution is the primary issue that needs to be addressed for any follow-on development efforts. Creating an even flow will allow the evaporator to use all of its area without creating liquid carry-over. This will allow the unit to reach heat rejection levels close to what was achieved when it was oriented upwards while avoiding the decrease in performance that liquid water in the header has been shown to cause. It will also eliminate the possibility of ice forming at the vapor outlet orifice. At the time of this writing there is an active effort at the University of Hartford to model the EDU coolant passages using computational fluid dynamics (CFD). This effort is intended to verify the assesment of uneven flow distribution and provide options for creating a uniform coolant flow. The model may also be used in designing the coolant passages for liquids such as propelyne glycol.

The issue of two phase flow in the feed water header was addressed by chilling the feed water to $40^{\circ} \mathrm{F}$. A flight unit could chill the water by adding a feed water heat exchanger 
layer onto the coldest of the MFE modules. The feed water would be chilled to the coolant outlet temperature in this layer before being fed to modules. The evaporant would absorb only a small amount of heat from the coolant, since the feed flow rate is an order of magnitude lower than the coolant flow rate and such a layer would weight less than one pound. Chilling the feed water is beneficial to both 1-g operations and microgravity operations because it would prevent impurities in the water from accumulating in the feed water orifice. If the MFE technology is applied to the moon or mars, it could also benefit by being installed in the upwards orientation. This would mitigate the two phase flow issue and boost performance beyond what was achieved in these tests.

\section{CONCLUSIONS}

An engineering development unit of the multifluid evaporator was built and tested at Hamilton Sundstrand. The EDU underwent check-out testing, thermal performance testing and thermal verification testing. The check-out testing showed that the test setup was adequate for the EDU and that the unit did not exibit histeresis. Thermal performance tests showed that the prototype should be able to reject $4.7 \mathrm{~kW}$ of heat with about $5 \%$ liquid water carry-over. The evaporant layer design can reject $6.0 \mathrm{~kW}$ of heat with significantly more carry-over. When the vapor header and orifice were attached the carry-over at the left and right edges of the EDU accumulated, causing a decrease in performance. The EDU could only reject $3.0 \mathrm{~kW}$ while maintaining manageable levels of liquid water carry-over. The vapor outlet orifices were successfully modified with rounded edges and a coating of Braykote to prevent ice from building up into the orifice. Future work on the MFE should focus on eliminating the presence of water carry-over at the edges so that the heat exchanger can be used at 100\% efficiency.

\section{ACKNOWLEDGEMENT}

I would like to acknowledge David Westheimer and Molly Anderson of NASA Johnson Space Center who funded the development of the EDU and the prototype. Acknowledgements are also due to the test operators who bore with us as we learned about the EDU on the fly and constantly updated our test plans.

\section{REFERENCES}

1. Anderson, M, Golliher, E., Leimkuehler, T., Quinn, G., "Preliminary Trade Study of Evaporative Heat Sinks." SAE 2006-01-2216. $36^{\text {th }}$ International Conference on Environmental Systems, Norfolk, July 17-20 2006.

2. Pangburn, T., "Progress in Evaluating Surface Coatings for Icing Control at Corps Hydraulic Structures" U.S. Army Cold Regions Research and Engineering Laboratory, Hanover, New Hampshire, Ice Engineering, Technical Note 03-4, October 2003. 